Letters to the Editor

NEUROSURGICAL FORUM

\section{Bridging the gap between administrative data and clinical observations}

TO THE EDITOR: We read with interest the administrative database study by Shweikeh et al. ${ }^{3}$ (Shweikeh F, Al-Khouja L, Nuño M, et al: Disparities in clinical and economic outcomes in children and adolescents following surgery for tethered cord syndrome in the United States. $J$ Neurosurg Pediatr 15:427-433, April 2015). The authors used the Kids' Inpatient Database (KID) to look at hospital discharge data for pediatric patients who had undergone tethered cord release (TCR) surgeries. Patient demographics, characteristics, complications, and utilization associated with these hospitalizations are described. The authors concluded that operative management has increased over time, and that there are significant differences in patient outcomes between age groups. They also concluded that their study is "highly supportive of surgery at a young age." Do the data and results support the conclusions?

Most importantly, we recognize that tethered cord syndrome (TCS) or TCR surgeries in this particular administrative database are challenging to identify with ICD-9$\mathrm{CM}$ diagnosis and procedure codes. Shweikeh et al. stated that they studied patients with the primary diagnosis of TCS who were treated with spinal laminectomy. We reviewed our institution's records to see how they compare to the authors' methods.

The authors use the following ICD-9-CM diagnosis code: 742.59 (other specified congenital anomalies of spinal cord). They label this group as "patients with a primary diagnosis of TCS." The authors then use one of the following 3 ICD-9-CM procedure codes to indicate that their selected patients had surgery for TCS: 03.59 (other repair and plastic operations on spinal cord structures), 03.09 (other exploration and decompression of spinal canal), and 03.4 (excision or destruction of lesion of spinal cord or spinal meninges).

We identified patients treated at our institution using these same codes: 742.59 and 03.59, 742.59 and 03.09, or 742.59 and 03.4 on hospital discharge data. We compared this list with patients in our surgeon-entered clinical database who underwent TCR surgery.

Using the ICD-9-CM code search algorithm, we identified 86 cases; 78 of the 86 patients $(90.7 \%)$ had some form of TCR surgery. However, there were 118 TCR surgeries in total in our prospective surgeon-collected clini- cal database, which is the gold standard of our practice. The sensitivity of the ICD-9-CM code search algorithm among patients with confirmed TCR surgery at our institution was 78 of $118(66.10 \%)$. Forty of our confirmed 118 TCR surgeries were not identified by the ICD-9-CM code algorithm used by Shweikeh et al. Both ICD-9-CM and clinical database cases included diagnoses entered in our database of fatty filum, tight filum, TCS, dermal sinus tract, lipoma, lipomyelomeningocele, tumor, arachnoid cyst, atretic meningocele, and diastematomyelia. Indications included syringomyelia, scoliosis, neurogenic bladder, lower-extremity symptoms, and other clinical symptomatology. Six patients ranging in age from 5 to 15 years had reoperations, which added to surgical complexity. Of note, the typical practice at our institution does not tend to include prophylactic surgery, such as fatty filum sectioning for incidental radiographic findings.

A known limitation in administrative database studies is often a lack of clarity in surgical indications. For TCR, this is an important issue. Practice variation exists in the threshold for offering surgery., ${ }^{1,2,5}$ Without the ability to identify the clinical indications, it may be spurious to draw conclusions about optimal timing of surgery or optimal candidates for surgery. The KID database does not offer enough information in this regard. Reoperations versus first-time surgery cannot be distinguished. Complications or sequelae diagnosed after hospital discharge are not recorded. The specific pathology associated with the label of TCS, or in the case of the study at hand (742.59, other specified congenital anomalies of spinal cord), is not known. Preoperative and postoperative levels of function are not known. For instance, the authors noted that older patients had a higher risk of nonroutine discharge, longer hospital stays, and complications than younger children. It is bold to conclude that surgery should be performed at a younger age without a lot more information. There are different populations who can fall into the highly heterogeneous cohort assembled by Shweikeh et al. Would it be fair to compare symptomatic teenagers having repeat lipomyelomeningocele surgery to infants undergoing prophylactic fatty filum sectioning?

We cannot be confident, based on our attempt at validation in our institution's patient population, that the authors' ICD-9-CM code algorithm actually studies TCR surgeries in a reliable or clinically meaningful way. We advise the utmost caution in drawing any conclusions about outcomes, disparities, or utilization using Shweikeh et al.'s study. 
In summary, without correlation with clinical practice, assumptions in this study may be misleading. There are known limitations inherent to this type of research. Acknowledging these limitations openly and fairly is valuable for all readers. Vigilant study design and data interpretation are crucial.

We urge readers to be critical and to have an open mind at the same time. We support big data research and support development of the field to make it useful to all. Part of this process is to learn what works and what is not possible with administrative data studies. For example, we need to examine codes in detail and aspire to validate them with institutional clinical data in the study process. A large amount of work needs to be done. This study on TCR surgery provides an opportunity for learning what works and what should be reexamined carefully.

The field of pediatric neurosurgery has not reached maturity relative to other specialties with big data research. We encourage the pediatric neurosurgery community to keep the dialogue open and work together to build a deeper understanding regarding the role of this research.

Sandi Lam, MD, MBA I-Wen Pan, PhD

Andrew Jea, MD

Thomas G. Luerssen, MD

Texas Children's Hospital, Baylor College of Medicine, Houston, TX

\section{References}

1. Drake JM: Occult tethered cord syndrome: not an indication for surgery. J Neurosurg Pediatr 104 (5 Suppl):305-308, 2006

2. Metcalfe PD, Luerssen TG, King SJ, Kaefer M, Meldrum KK, Cain MP, et al: Treatment of the occult tethered spinal cord for neuropathic bladder: results of sectioning the filum terminale. J Urol 176 (4 Pt 2):1826-1830, 2006

3. Shweikeh F, Al-Khouja L, Nuño M, Johnson JP, Drazin D, Adamo MA: Disparities in clinical and economic outcomes in children and adolescents following surgery for tethered cord syndrome in the United States. J Neurosurg Pediatr 15:427-433, 2015

4. Tuuha SE, Aziz D, Drake J, Wales P, Kim PC: Is surgery necessary for asymptomatic tethered cord in anorectal malformation? J Pediatr Surg 39:773-777, 2004

5. Valentini LG, Selvaggio G, Erbetta A, Cordell R, Pecoraro MG, Bova S, et al: Occult spinal dysraphism: lesions learned by retrospective analysis of 149 surgical cases about natural history, surgical indications, urodynamic testing, and intraoperative neurophysiological monitoring. Childs Nerv Syst 29:1657-1669, 2013

\section{Disclosures}

The authors report no conflict of interest.

\section{Response}

We appreciate the valuable comments and summary of our work by Drs. Lam, Pan, Jea, and Luerssen with regard to our use of the KID to study disparities in clinical and economic outcomes in children and adolescents following surgery for TCS. Studies based on the KID are prevalent in the pediatric neurosurgical literature. ${ }^{1-3}$ We recognize and fully acknowledge the limitations inherent in admin- istrative databases, and, specifically with the KID, related to coding. However, despite the obvious limitation, the KID is the only all-payer pediatric inpatient database containing information relevant to pediatric neurosurgical operations. The KID provides a large sample size that tends to yield estimates with much smaller standard errors when compared to smaller databases. ${ }^{4}$ Without a sample of several million, as provided by the KID, estimates for less common procedures and diagnoses are unreliable and often unavailable.

The criticisms raised by the authors in their letter are certainly valid, and we appreciate their in-depth review of our paper, especially the comparison of their institutional data to that which we gathered from the KID. The fact that there were differences in the 2 data sets is concordant with the idea that the KID provides national and regional estimates of hospital inpatient stays by pediatric patients, enabling analyses of relatively rare conditions, such as tethered spinal cord, and the treatments offered. It is not unexpected that statistical analysis of the KID could lead to some conclusions that may differ from an individual or institutional practice. These differences enhance the literature and demonstrate that regional variations in care exist.

It is our belief that, despite limitations, there is value in analyzing administrative databases. It is our hope that pediatric neurosurgeons will continue to collaborate and create multiinstitutional databases to not only increase the sample size of various studies, but also to showcase regional variations in care. Peer review of outcomes in the context of these variations could lead to the designation of best practices for specific disease conditions encountered by all pediatric neurosurgeons.

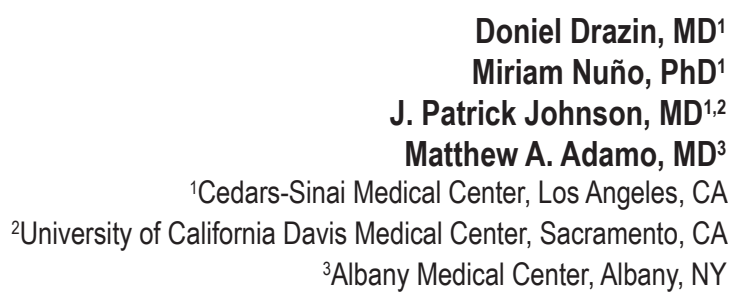

\section{References}

1. Attenello F, Tuchman A, Wen T, Nallapa S, Christian E, Cen SY, et al: Infection rates following prolonged time to open neural tube repair: a national study. Neurosurgery 62 (Suppl 1):229, 2015 (Abstract)

2. Pestana Knight EM, Schiltz NK, Bakaki PM, Koroukian SM, Lhatoo SD, Kaiboriboon K: Increasing utilization of pediatric epilepsy surgery in the United States between 1997 and 2009. Epilepsia 56:375-381, 2015

3. Piatt JH Jr: Pediatric spinal injury in the US: epidemiology and disparities. J Neurosurg Pediatr 16:463-471, 2015

4. Whalen D, Houchens R, Elixhauser A: 2003 HCUP Kids' Inpatient Database (KID) Comparison Report. HCUP Methods Series Report \# 2006-03. Rockville, MD: US Agency for Healthcare Research and Quality, 2006

\section{INCLUDE WHEN CITING}

Published online January 29, 2016; DOI: 10.3171/2015.8.PEDS15481.

@AANS, 2016 


\section{Let well alone: can the endoscopic extended endonasal approach to the lateral orbital apex be considered as minimally invasive?}

TO THE EDITOR: I read with interest the article by Dziedzic et al. ${ }^{3}$ (Dziedzic TA, Anand VK, Schwartz TH: Endoscopic endonasal approach to the lateral orbital apex: case report. J Neurosurg Pediatr 16:305-308, September 2015). The authors described an unusual endoscopic endonasal approach to the lateral orbital apex, which was performed to resect a rhabdomyosarcoma in a 4-year-old child. The procedure included a binasal endoscopic approach with posterior resection of the nasal septum, ethmoidectomy, opening of the maxillary sinus through its medial but also superior wall, and drilling of the perpendicular plate of the pterygoid bone. In contrast to endoscopic endonasal approaches to the medial aspect of the orbital apex, ${ }^{2}$ approaches to the lateral compartment of the orbital apex via this endonasal route remain challenging. For most neurosurgeons and ENT surgeons, the description provided by Dziedzic et al. may appear to represent a "minimally invasive" approach. I would consider removal of the posterior nasal septum, the perpendicular plate of the pterygoid process, and the medial and superior walls of the maxillary sinus in a 4-year-old child to reflect a procedure that is not minimally invasive and that the authors' approach could lead to interference with air flow in the sinonasal tract as well as to rhinological morbidity such as crusting and chronic sinusitis. Elsewhere in their article, the authors discussed removal of the maxillary sinus roof (which corresponds to the orbital floor), but they did not report performing any reconstruction, without which the child could be at risk for enophthalmos, inferior rectus muscle trapping into the maxillary sinus, and in turn possible diplopia. Numerous "minimally invasive" routes to the lateral orbital apex have already been described; these are straightforward and are associated with excellent oncological control of the tumor margins while avoiding any significant risks to the lateral rectus muscle and the optic nerve. ${ }^{1,4,6}$ These approaches include the lateral orbitotomy performed through an eyelid or an eyebrow incision, which has the advantage of producing an outstanding cosmetic result and having a very short surgical time while offering a substantial reduction in blood loss (this is a pertinent anesthetic consideration, particularly in young children, keeping in mind that the endonasal approach may be associated with substantial blood loss) and time. ${ }^{5}$ If the authors are very reluctant to cause any cosmetic scarring, we propose a sublabial endoscopic transmaxillary approach to reach the inferior and lateral orbital apex; this approach avoids the posterior septectomy and pterygoid drilling, providing a more straightforward and less oblique trajectory (i.e., it is the endoscopic equivalent of a Caldwell-Luc approach). The authors have described a novel approach to the lateral orbital apex, which should, in my opinion, neither be considered as minimally invasive nor be proposed as a first-line option; rather, it should be merely included in the armamentarium of procedures available to skull base surgeons.

Moncef Berhouma, MD, MSc

University Hospital, Lyon, France

\section{References}

1. Abouchadi A, Capon-Degardin N, Martinot-Duquennoy V, Pellerin P: [Eyelid crease incision for lateral orbitotomy.] Ann Chir Plast Esthet 50:221-227, 2005 (Fr)

2. Berhouma M, Jacquesson T, Abouaf L, Vighetto A, Jouanneau E: Endoscopic endonasal optic nerve and orbital apex decompression for nontraumatic optic neuropathy: surgical nuances and review of the literature. Neurosurg Focus 37(4):E19, 2014

3. Dziedzic TA, Anand VK, Schwartz TH: Endoscopic endonasal approach to the lateral orbital apex: case report. J Neurosurg Pediatr 16:305-308, 2015

4. Lyson T, Sieskiewicz A, Rogowski M, Mariak Z: Endoscopic lateral orbitotomy. Acta Neurochir (Wien) 156:1897-1900, 2014

5. Nemet A, Martin P: The lateral triangle flap-a new approach for lateral orbitotomy. Orbit 26:89-95, 2007

\section{Disclosures}

The author reports no conflict of interest.

\section{Response}

We thank Dr. Berhouma for his careful comments. He stated that the approach described in our paper, namely the endonasal transpterygoid approach, is not a minimally invasive approach since there is destruction of a significant portion of the nasal architecture, which can "lead to interference with air flow... as well as to rhinological morbidity such as crusting and chronic sinusitis." He also indicated that removal of a portion of the floor of the maxillary sinus could lead to enophthalmos, inferior rectus trapping, and diplopia. He suggested that a more minimally invasive surgery would involve an eyebrow, eyelid, or sublabial incision. Our first response is that we have not called the endonasal transpterygoid approach a "minimally invasive" approach, but rather a "minimal access" approach to highlight the fact that it utilizes a natural corridor, namely the nostrils, as opposed to making an incision as Dr. Berhouma proposed. We prefer the phrase "minimal access" precisely because it does not convey a lack of invasiveness given that the approach can be quite invasive, as the author points out, once the access is achieved. Dr. Berhouma also raises a list of many potential complications, none of which actually occurred in our patient. Similar risks can be associated with the lateral orbitotomy, such as diplopia, lateral rectus palsy, and enophthalmos. Moreover, we have studied nasal quality of life in our patients following endonasal endoscopic surgery and find that although transient worsening can occur, nasal function returns to baseline within 3 months of surgery. ${ }^{1-3}$

Theodore H. Schwartz, MD Vijay K. Anand, MD Weill Cornell Medical College, NewYork-Presbyterian Hospital, New York, NY 


\section{References}

1. Bedrosian JC, McCoul ED, Raithatha R, Akselrod OA, Anand VK, Schwartz TH: A prospective study of postoperative symptoms in sinonasal quality-of-life following endoscopic skull-base surgery: dissociations based on specific symptoms. Int Forum Allergy Rhinol 3:664-669, 2013

2. McCoul ED, Anand VK, Schwartz TH: Improvements in site-specific quality of life 6 months after endoscopic anterior skull base surgery: a prospective study. J Neurosurg 117:498-506, 2012

3. McCoul ED, Bedrosian JC, Akselrod O, Anand VK,

Schwartz TH: Preservation of multidimensional quality of life after endoscopic pituitary adenoma resection. J Neurosurg 123:813-820, 2015

\section{INCLUDE WHEN CITING}

Published online February 26, 2016; DOI: 10.3171/2015.11.PEDS15682.

CAANS, 2016 